\title{
Pre-marital Relationships and the Family in Modern India
}

\section{Parul Bhandari}

\section{(2) OpenEdition}

\section{Journals}

\section{Electronic version}

URL: http://journals.openedition.org/samaj/4379

DOI: $10.4000 /$ samaj.4379

ISSN: $1960-6060$

\section{Publisher}

Association pour la recherche sur l'Asie du Sud (ARAS)

\section{Electronic reference}

Parul Bhandari, « Pre-marital Relationships and the Family in Modern India », South Asia

Multidisciplinary Academic Journal [Online], 16 | 2017, Online since 31 August 2017, connection on 30 April 2019. URL : http://journals.openedition.org/samaj/4379 ; DOI : 10.4000/samaj.4379

This text was automatically generated on 30 April 2019.

\section{(c) (i) $(9)$}

This work is licensed under a Creative Commons Attribution-NonCommercial-NoDerivatives 4.0 International License. 


\title{
Pre-marital Relationships and the Family in Modern India
}

\author{
Parul Bhandari
}

\section{Towards local interpretations of love marriage}

1 The binaries of "arranged" and "love" marriage have been popularly used to make sense of changing marriage practices in contemporary India, where the former is seen as a signifier of a traditional India and the latter an indicator of change, progress, and modernization. However, scholarship has problematized this simplistic binary conceptualization, arguing that elements of "choice" are also present in arranged marriages (Sharangpani 2010; Titzmann 2011), and that the reality of marriages is best captured in the use of in-betweens as in the case of arranged-love marriages (Uberoi and Singh 2006).

2 There is, however, also substantial focus on analyzing "love" marriages, as recent ethnographic works note that "love" is seen as an important trope for asserting modern identity in a globalizing world (Donner 2016; Hirsch and Wardlaw 2006; Twamley 2014) and provides insight into the contemporary values of individualism, entrepreneurship, and "enterprise culture" that drive much of India's post-liberalization economy (Gooptu 2013). Whilst reiterating the feelings of love and choice, these works also critique the "modernist narratives of gradual and linear changes in marital practices from arranged marriages to self-chosen unions," explaining that there are local experiences and interpretations of love marriages (de Neve 2016:1249). They allude to a new set of intimacies and desires of the young, in particular, companionate marriages, emotional compatibility, and generally the notion of choice that dominate the discourse on marriages (Donner 2016; Fuller and Narasimhan 2008; Lietchy 2003). A central feature of these diverse local experiences of the variations of "love" marriage is the continued importance of parental support and approval of the family. For example, Donner (2011, 2016) in her study of the middle class in Kolkata explains that whilst love and choice in marriages are important to claiming a modern self, the involvement and approval of the 
family remains intact. In fact, delineating the significance of the family, Donner goes on to argue that, more than consumption, it is the family that continues to shape the middle class identifications of modern India. Similarly, Fuller and Narasimhan $(2008,2014)$ in their study of IT sector employees in Tamil Nadu, argue that the young middle class desire to marry a spouse with whom there is interpersonal compatibility; however, this choice is exercised within the rules of caste endogamy. In a comparative study of Indians in Gujarat and second generation Gujarati Indians settled in the UK, Twamley (2014) explains that whilst these two sets of youth have differing conceptions of love and intimacy, they both place a strong emphasis on gaining parental approval in their choice of spouse. In a study of middle class in Kathmandu, Lietchy (2003) also notes that for the middle class subjects modern attitudes do value love but also seek parental consent. These experiences can often be described as "love-cum-arranged" marriages as a selfchosen alliance turns into marriage only after parental approval: "even though the couple may have chosen each other, they will have obtained parental consent, even if only after protracted arguments and disagreements" (de Neve 2016:1224). Furthermore, works on technologies of matchmaking (Agrawal 2015; Bhandari 2014; Titzmann 2013) have also outlined the specific ways in which matrimonial websites, for example, promote what Titzmann calls "family oriented individualism," ensuring that the desires of both the individual and the family are met in the spouse-selection process.

The importance of parental approval or lack thereof in "love" marriages is best captured by the ethnographic works undertaken by Grover (2011) and De Neve (2016), who evaluate the post-marital arrangements of those who opted for "love" marriages. Grover explains that in comparison to arranged marriages, love marriages are less likely to suffer a breakdown, not because these marriages are more egalitarian and empowering for a woman, but because the woman does not have any parental support to leave the marriage (2011:9-10). De Neve (2016), in his work on the migrant work force of Tirrupur in Tamil Nadu, traces those love stories where the parents renounced support for their children upon their choice marriage. This withdrawal of support by the parents, as the young men narrate, adversely effects their financial position and professional mobility, leading the men to claim that if given another chance they will opt for an arranged over a love marriage.

Whilst de Neve and Grover explore the post-wedding arrangements of love marriages, in this article, I place emphasis on the pre-marital experiences, which may or may not convert to marriage. Following the works enlisted above, I explain the ways in which the family and the moral framework of parental approval is applied to pre-marital relationships, which are viewed by the youth as symbols and spaces of their individualism, freedom, and initiation into the modern world of opportunities.

\section{Mapping Pre-marital Experiences}

5 In this article, I place emphasis on what has been called the phase of "elongated singlehood," where young adults (aged 24-31) are pushing the age of marriage (to 28-29) primarily to acquire professional mobility. ${ }^{1}$ There are differing expectations for men and women with regard to age at marriage, as women come under more pressure to marry "early." Yet in my research sample there were women who were 30 and unmarried, just as there were men who were 28 and married or engaged to be married. Nonetheless, women's age at marriage was a matter of concern for them and their families, as the men 
and their family preferred the bride to be a younger woman. Despite this pressure the women were ready to increase their marriage age for professional pursuits and the desire to find a suitable spouse. Men and women appropriate this phase of "non-marriage" to experience diverse romantic encounters, and subsequently this phase is associated with ideologies of individualism, freedom, and liberty. The perspective that premarital relationships are expressions of individualism is further propelled by the fact that these experiences take place in the "away from home" space (Scalco 2016), that is, at work or in leisure spaces that are not immediately under the surveillance of the family. These encounters are therefore further romanticized, for their inception, as the young middle class argue, is based solely on the "individual" dynamics and emotional compatibility of the couple.

6 Real as these narratives are, I reveal in this article that these experiences in fact abide by the moral frameworks set by the family. In so doing I argue that the family controls these relationships, shaping their dynamics, and approving or disapproving them. Such is the importance of family even in defining pre-marital relationships that as the relationship takes a more serious turn the partners gauge each other on their ability to "fit in" with their family, at times by actively disciplining their partner's behavior.

7 I thus explain the myriad, often contesting, affections, emotions, and perceptions associated with pre-marital relationships, which on one hand are viewed as the epitome of individualism and the stepping stone of the desire to write one's own biography (Beck 1992, 2000), and on the other hand are enmeshed in the performances of familial duty and fulfilling parental expectations. These contestations and contradictions, however, are not necessarily seen as binary opposing categories, but as complementary aspects of the project of modern self-making, and are seamlessly interwoven into the romantic experience. ${ }^{2}$

8 I put forth my analyses in three parts. In the first part I explain that the young adults view pre-marital relationships as a largely individualistic experience as they revel in the opportunity to now write their own biography. In the second part I reveal that this image does not necessarily hold for long, as soon a moral framework set by the family is introduced to the relationship. This evokes certain practices of disciplining to ensure that the chosen partner matches the expectations of the family. In the third part of the article I bring attention to the direct involvement of the family in shaping the future of the relationship. I explain, however, that the family presents itself as merely guiding the relationship, which, I argue, is a crucial step for the modern self-fashioning of the family.

\section{Fieldwork}

9 This paper is based on ethnographic fieldwork on the middle class youth of New Delhi, which involved, other than participant and non-participant observation, in-depth interviews with a 100 men and women aged between 24-31, employed at multinational companies, as well as interviews with about 25 parents. Though the fieldwork site was Delhi, the interviewees were not all born and brought up in Delhi; several had migrated from cities including Jaipur, Ranchi, Patna, for higher education and stayed on to be employed in multinational companies. Whilst there was no restriction on the caste and religious composition, the representation was mainly of upper-caste Hindus, in line with the argument that the category of the middle class is a skewed composition of the upper castes (Deshpande 2003; Fernandes 2006; Jodhka and Prakash 2016). The middle class, as 
much scholarship has established, remains fuzzy and difficult to define, and for this paper I focused on a specific segment of the middle class population that is popularly described as the "neoliberal middle class," as they choose to be employed in the private sector, particularly the multinational companies that set up their offices in India after the 1990s liberalization reforms. ${ }^{3}$ It is also to be noted that this sample self-identified themselves as being middle class (and not upper middle class), despite the fact that there were substantial variances in their economic and social status; some belonged to families of small or middle-income tradesmen living in smaller cities, whilst there were also those whose parents were high-status government employees or businessmen living in Delhi. What brought them together was their high salaried employment after achieving competitive educational and professional degrees (beginning from Rs. 50,000 per month going up to Rs. 5 lakhs), and a unique globally-oriented lifestyle involving foreign travel and engagement with global work cultures. The specific class position of this sample limits its generalizability and representativeness; nonetheless, it remains important for analyses as this class is seen as an appropriate symbol of a "global India."

Whilst I did trace the lives of both men and women for this research, this particular article focuses more on the voice of women than men, because women were more vocal about their experiences of disciplining by their boyfriend or fiancé's family. Men, on the other hand, did not narrate such experiences of control and surveillance, not necessarily because they did not undergo these strategies of disciplining, but perhaps because they were not comfortable discussing these issues with a woman interviewer. ${ }^{4}$ Furthermore, the men, much more than women, narrated their attempts to change the attitudes of their girlfriends in order to suit their family values. This desire to "change" and to some extent the confidence that women would indeed change their attitudes is indicative of the patriarchal outlook of these relationships.

\section{Curating an Individualistic Experience}

11 In the early 1990s India undertook certain economic liberalization reforms ushering the Indian state into a "new" era (Fernandes 2011; Varma 2007). As the economy "opened," more opportunities for professional ambitions emerged, especially for the middle class, who extended their domination to the private sector as well (Jodhka and Prakash 2016). Acquiring a well-paid private sector job, particularly in multinational companies, as my young interviewees and their parents explained, became a dream the middle class aspired to, as along with offering high salaries, it allowed an opportunity for "exposure" to urban and global ways of life. This new set of professional opportunities lead people to move to the urban areas of Delhi, particularly Gurugram (formerly Gurgaon), where the offices of all multinational companies are located. To facilitate their commute, some employees also rented apartments in Gurugram, visiting their family in Delhi over the weekends.

In some senses, the work-place occupies a liminal state between Scalco's distinction of "Home" and "Away from Home." The former, according to her, constitutes those spaces where people find themselves under acute scrutiny, or where life is governed by familylike sociality. On the other hand, "Away from home" refers to those spaces where individuals have the potential to "evade familial control" (2016:327). Scalco clarifies that there are no strict boundaries between these two social spaces, and it is the fictive separation that is more crucial to the self-fashioning and understanding of her interviewees (2016:327). This analysis can appropriately be extended to my ethnographic 
research, where I found that the work place, an educational institute or leisure cultures formed the "away from home" space for my interviewees. Whilst even in these situations the individual did find themselves under scrutiny from colleagues, there was, however, no direct surveillance by the family and the nature of the surveillance differed as well. For example, they were rarely called out on their behavior instantly with strong reprimand, as would happen in a family-controlled space.

13 The "away from home" spaces are ever increasing, including not only work spaces but also leisure cultures facilitated by the transforming urban landscape, with the building of malls, bars, cafes and other such public spaces (Brosius 2010, 2013; Mazzarella 2002; Srivastava 2014). As Brosius notes: "new social and physical spaces have emerged in metropolitan centers with economic liberalization, enabling urban youth to meet, in principle in less socially regulated ways. These places could be colleges (even schools), malls, cinema halls, clubs, bars, or cafes" (2013:272). Another factor promoting these attitudes and aspects of pleasure, consumption, hedonism, and feelings of "individual space and control," is the increasing use of technology in everyday lives that also allows for a virtual and instant "away from home" spatiality. In fact, much recent scholarship in media studies has shifted attention to the impact of media on intimacies and selfhood (Gershon 2011; Miller 2011). Together these spaces and places of "away from home" infuse the youth with feelings of "writing their own biographies" (Beck 1994; Giddens 1991). These feelings of individuality and freedom also extend to their romantic lives as they begin to date or choose romantic interests, not necessarily in view of marriage.

My interaction with middle-class youth revealed that they categorized these experiences on the basis of sexual involvement and "seriousness" or degree of commitment in the relationship. Some experiences are mainly sexual in nature and usually limited to a short period of time, at times consisting of only one encounter, and are referred to as "onenight stands." The term "dating" is used for a longer period of being with together, without necessarily any commitment to marriage, and at times involving sexual relationships. It is the terms "serious" and "long-term" that are used to denote a relationship that is intended to be transformed into marriage. At times, these relationships also involve live-in arrangements, though this form of intimacy or romantic arrangement in which the couple lives-in before marriage is still not widely accepted. At other times they were also "distance" relationships, when partners lived in different cities for career-related reasons. It was also the "serious" relationship that was more publicly accepted and displayed, much more especially than "one-night stands." These categorizations seem to be influenced by public representations and discourses of romantic relationships and sex, which in various forms, since the early 1990s, have increasingly appeared in the medium of cinema, television commercials, and celebrations of love and romance. ${ }^{5}$ For example, in another work I have noted that the Bollywood films of the past decade, including Break ke Baad (After the break, 2010) Shudh Desi Romance (Pure Desi Romance, 2013), Ye Jawani hai Deewani (This Youth is Crazy, 2013), and Tamasha (Spectacle, 2015), tell stories of "pre-marital relationships, including break-ups, and struggles to find 'self' in the contemporary nexus of profession, money, and love, and also live-in relationships"(Bhandari 2017:3). ${ }^{6}$ In fact, it can be argued that Bollywood cinema has enabled a greater public discourse on pre-marital relationships, so much so that the terms "boyfriends" and "girlfriends" appear more candidly in intergenerational interactions. Mazzarella writes of the contributing effect of advertising-especially of 
condoms-in the 1990s, which challenged the "public morality and austerity aesthetic of Gandhi and Nehruvian quality," indicating that sex can also be for pleasure and fun (2003:60). Analyzing the rise in the depiction of romantic and erotic love in public, Brosius explains the significance and popularity of Valentine's Day, which though "unspectacular, if not irrelevant" for her interviewees, nonetheless, "contributed to the circulation and spread of romantic, eroticized love as a legitimate element of lifestyle" (2013:269). The reason for this privileging of Valentine's Day, she notes, is that

for the first time in postcolonial India, romantic love became part of a rhetoric of a seemingly unrestricted way of life in which decision making is allegedly based on two people in love with each other... Valentine's Day promoted an individual's choice for a partner, legitimated the desire to be "in love" without necessarily wanting to be married to the same person... (2013:256).

Brosius' findings resonate with the experiences of my interviewees, for it was amply clear that their romantic encounters are not only motivated by feelings of love and care, but are also imbued with expressions and realizations of freedom and individuality. This is specifically because the decision to enter into a romantic experience and the process undertaken to do so is not under the explicit guidance of parents or family.

Raj, is a 27 year old project manager at a leading multinational company in Gurugram. ${ }^{7}$ His parents live in west Delhi, making the commute to his work place rather tiring. So in the second year of his employment he, along with two of his other colleagues, rented an apartment in one of the residential areas in Gurugram. When Raj joined the workforce at 23 , he started dating a colleague but that did not last for long, for they "grew apart" he said. About two years ago, he started dating another colleague with whom he is now in a "serious" relationship. Raj clarified that his parents did not know about either of these relationships. He said,

See, with the first one it was a short-term relationship so I never ended up telling my parents about her. The thing is I don't want my parents to think that I go to the office to do all this! Especially when it is not serious. Also, I was quite young back then... I am very close to my parents, don't get me wrong, but I also like the idea that I have my own life away from them and that I am not always answerable to them. When things get serious and when I know someone will be an important part of my life, I will surely tell my parents...

Sunaina is a 26 year old who is working as an analyst at a leading international bank. In narrating her romantic experiences Sunaina explained she feels less under surveillance with her more recent relationships than the ones she had whilst in university. She said,

Back in college the parents had much more control. They were always worried, constantly checking on me. I of course had boyfriends then also, but it was a bit difficult to be absolutely free to meet them and go out. There were so many tensions and distractions: parents, friends, exams, the worry of a future. But things change when you get your first job. You are a lot more settled, you are making money, and also the control from parents reduces. Also, they begin to treat you as adults.

Sunaina very clearly specifies a break in her experiences of romance with her new journey in life, that of employment, associated with which are feelings and expressions of more individual control, freedom of movement, and a sense of liberation from the everyday surveillances of home. She goes on to explain,

My job involves a lot of traveling so I am away from home. In fact, I met my first boyfriend on these official trips. He and I were both in the same team, and we spent so much time together traveling and communicating with each other and got used to each other. The relationship however soon ended as we realized we don't match 
that much after all... I met my current boyfriend also through office. He is a part of the Mumbai team and we met at a workshop. We just clicked and since then have been in a long-distance relationship.

Like Raj, Sunaina also did not reveal her relationship to her parents. She said, You know how parents are. They get all excited and want to make enquiries and immediately see your boyfriend as a suitable boy [for marriage]. This makes me uncomfortable. I mean I don't want that sort of pressure yet. I am living a good life, working, hanging out with friends, traveling, and I don't want my parents to start with all the enquiries and pressure so early. Also, I need to assess the guy myself first. What if I don't like him after a few months... I need some time to be sure too, and then I will introduce him to parents....

The rationale behind not disclosing a romantic encounter to parents was routinely explained in other interviews too. These encounters become a boundary marker of a personal life separate from that of the family. These opportunities of romance are also used as opportunities to experience other aspects of socializing that fall outside the realm of familial sociality, including traveling with the partner, going out for dinners, and partying/clubbing. In other words, through the opportunity of romance the young middle class also seize further opportunities of leisure and socializing that are not controlled or dictated by the family. In doing so, they show that these relationships are not simply about intimacy and love, but also about individual experience, freedom, and control over life decisions. The young professionals also realize that this private experience will not last for long, given the social and cultural significance of marriage, so they desire to protect these experiences from the scrutiny of parents. Whilst recent works (Donner 2011, 2016; Lietchy 2003; Saavla 2012; Twamley 2014) have explained the importance of love and choice in the self-fashioning of the modern for the middle class, I argue that experiences of short-lived and long-lived relationships are equally significant constituents of being modern.

However, this experience of individual freedom and choice soon gives way to a consensual and discussed decision on the suitability of the chosen partner as the youth begin to involve their parents in the relationship. The potential of marriageability as a result of their romantic encounter is adjudged and approved within a familial framework. In fact, in order to ensure that their family approves of their choice, the very relationship that was concealed from the parents and championed as being individual-centric begins to be disciplined and shaped to meet the family's requirements and desires.

\section{The Moral Framework of the Family}

Being in a pre-marital relationship, in many senses, is a liminal state that might transform into marriage, for it is here that the partner (in particular the woman), is most obviously disciplined and who, as a response, might either resist the controlling behavior leading to the breaking up of the relationship or agree to be molded. In this section I bring attention to certain techniques of disciplining and surveillance that operate within a moral framework established by family values and expectations. These narratives lopsidedly address the attempts to discipline women, for my research revealed that women were under far greater pressure to be a suitable partner, thereby reiterating the societal norm of hypergamy and patriarchal living, wherein the woman is tamed to adjust to the man's family. 
One such sphere in which the woman was much more harshly scrutinized than the man was that of sexual activity. The obsession with a woman's virginity is well-established by the central ritual of a Hindu marriage, that of kanyadaan (gift of a virgin), as well as through a social conditioning whereby the suitability of the girl is determined by her control over her sexual self, which is established through a rigorous process of socialization both within the home and outside it (Dube 1988; Fruzetti 1982). Whilst both men and women reveled in experiencing different intimacies, it was striking that even in pre-marital relationships, women were far more harshly judged for their sexual activity than men, a scenario which is not very different from the formal search for a spouse. Whilst I rarely encountered men who insisted on dating or marrying a woman who was a virgin, they were certainly concerned about her sexual past. The men claimed that as long as the woman was in love with a man, a sexual relationship was only natural. However, they frowned upon the possibility that the woman may have been sexually active with multiple partners, including indulging in "one-night stands." Though the term "morally loose" was not used, the references to women with an active sexual past implied a strong undertone of immorality and "loose" character. These opinions were upheld even by those men who themselves had an active sexual past with multiple partners. The women, on the other hand, rarely desired a virgin man and were less scandalized by a man's sexual past, often citing not the patriarchal mindset with regard to sexual mores, but claiming that times are changing, and both men and women are more sexually active. In other words, women seemed more accepting of sexual experiences for both themselves and the men, whereas men were reluctant to accept woman's sexual histories.

\section{Disciplining}

I met Reema, a 26 year-old Chartered Accountant working in a reputed multinational consultancy firm, for coffee at a South Delhi café. A meeting scheduled for two hours turned out to be a four-hour conversation where she narrated, with much candor, her desires and struggles in her relationships, in particular the current one that had a history of ups and downs as it entered its fifth year. Reema's parents migrated to Africa when she was a small child and when she turned 16, she returned to India with her younger sister, to live with her grandparents and pursue higher education. Reema decided to stay on in India, and after completing her graduation degree, she took a job in a leading multinational firm. Reema met her boyfriend, Manu, in college and started dating in the final year. She said,

We were really good friends and then a friend suggested that our chemistry is so good that we should be together. Bas [That's it] we soon got together ... It has been quite a journey. Manu is a very caring person and watched out for me especially because my parents don't live in India. But the thing is I am from a professional family and a Kayastha (caste group) background and he is from a business Marwari family, so, many differences crept up, mostly because he wanted me to be like the other Marwari girls who stay at home!

I further enquired as to what sort of expectations he had of her. She explained, I am a very strong independent girl who has been taught to speak her mind. In fact, this is what he liked about me when we started dating. All other girls were so submissive and girly, but he was attracted to the fact that I had a mind of my own and that I was career driven. I mean I cracked the CA [Chartered Accountancy] exams all in the first attempt, within three year. ${ }^{8}$ However, about two years ago, 
when he started getting serious and talking about marriage he started finding faults in me, and disliking things that he previously liked! He would tell me that I should learn to adjust and fit into their family. Like I should wear saris [a female garment, typically wrapped around the waist with one end draped over the shoulder], not talk too much in front of others, or give my "expert" opinions [she said rolling her eyes].

Reema detested these attempts to "tame" her, she said. In fact, they had broken up a few times over these issues and when I interviewed Reema she was indeed on one of her "time-outs" with him. Reema desired a better compatibility with a partner, but she was not yet convinced she wanted to totally give up on the relationship for they had so much "history." she narrated with much empathy that her boyfriend had been a strong support system for her especially since her parents were not living in India. However, she was also not ready to become a typical Marwari daughter-in-law, and hoped to negotiate her way into their relationship.

Other women too narrated their experiences of being "tamed" by their boyfriends to become more appealing to their family. As I dined with four young women at a restaurant in Gurugram, the conversation immediately shifted to the struggles of being a good girlfriend and their long list of controlling boyfriends. Shweta, who holds an engineering degree from one of the most reputed institutes in India, narrated her romantic experience with Amit. Amit presented himself as a highly independent and self-made man, who respects his family but was not the usual "mama's boy." However, once they started dating and the relationship took a serious turn, shweta soon found herself bombarded with expectations to mingle with the family and earn their approval, by minding "small" things like her eating habits and dressing style. She said,

As we got deeper in the relationship, I realized that his family's approval is of paramount importance to him. Not that I have a problem with that, but then I was expected to appease them. Like when I was expected to go see them he said I should also wear Indian clothes. Also, we both enjoy eating meat, however, in his house everyone is a vegetarian, so I was told not even to mention that I eat meat and drink alcohol. I don't have a problem with adjusting and respecting their lifestyle, but to lie about who I am makes me feel like an outcast, like there is something wrong in who I am.

Despite Shweta's reluctance to adhere to these specific demands by Amit, she decided to play along on the condition that she would not follow these expectations upon marriage. They suspected that his parents would perhaps take longer to accept her non-vegetarian eating habits, so they agreed that she would not eat meat in front of them, but she insisted that after a few years of marriage and especially upon the birth of their children she would no longer hide her dietary preferences. Shweta accepted these disciplining conditions only as strategies for approval of their union and made it clear to Amit that she intended to abide by them only temporarily.

Scholarship on Indian marriages has certainly noted extensively and theorized the importance of family in the process of spouse-selection. However, the very act of meeting the parents for the first time has not received the attention it deserves. In my interviews with the young middle class, I found that much anxiety and preparation governs the first time a boyfriend or girlfriend meets the parents. In fact, the practices of disciplining are to prepare for the first and subsequent meeting with the parents.

23 Akash, aged 29, who is an MBA graduate, described the feelings of nervousness, anxiety, and jitter that he experienced the first time he "formally" introduced his girlfriend-who was his batch mate at the MBA institute-to his parents. He said, 
My girlfriend is from the Northeast part of India. She was brought up in Mumbai but she belongs to Assam, and their culture is different than our culture [referring to the fact that he belongs to Uttar Pradesh, a northern state of India]. There are little things like wearing a sari or salwar kameez (Indian attire: a long top and loose pants), and covering up, using the duppatta (scarf), and not being too sharp with the tongue. My girlfriend is a smart independent urban woman and to her maybe this environment will be alien. So, I have been training her [raises his eyebrows and smiles] to be a certain way when she meets my parents.

When I asked Akash if he, like his girlfriend, was anxious on his first meeting with her parents, he responded that he "of course" was nervous and wanted to make a good impression on them. However, he was also quick to add that he was surely under "less" pressure to impress than his girlfriend would have been, given the "nature of our society," he said.

\section{Surveillance as Cornerstone of Relationships}

These romantic relationships also modeled themselves on the framework of the family in another way, namely, the exercise of control and authority externalized through surveillance. This is indeed notable, for often men and women resist surveillance from their parents, fighting for individual space and freedom. However, this same space is soon occupied by a boyfriend or girlfriend, who puts the partner under strict surveillance. This was amply clear in my attempts to schedule interviews, where at times, instead of getting permission from parents, my interviewees discussed my request to meet them with their boyfriend or girlfriend. The boyfriends were keen to know the kind of questions I would ask, most fearing feminist conversations on their relationships or in depth discussion of past relationships. The girlfriends, on the other hand, seemed insecure and suspicious as to why a young woman would request a private conversation with their boyfriend. In either case, it was rather evident that the authority and control had shifted, now lying not with the parents but a romantic partner, who thereby still held up the principle of accountability that governs family dynamics.

One such experience was when I scheduled an interview with Sneha, a 27-year-old working in a multinational company. I met Sneha earlier at a house party hosted by another interviewee where she showed interest in my topic of research and joked that her life story would form an interesting case. I asked to schedule an interview with her and she immediately agreed. When she arrived at the café, however, she seemed a bit reluctant, and as soon as we sat down she said, "I have a request. My boyfriend wants to listen to our conversation. Can I put him on speaker phone?"

This was the first time that I had encountered this request and I explained to her that the purpose of the interview was for her to open up, relax, and talk about private experiences, especially of her past, and if her boyfriend were with her [even virtually] she would not be able to do so. Whilst she agreed with me she was petrified of her boyfriend, who insisted that he be made privy to our conversation. She looked at me and said, "He is insisting. I can't help it."

27 I then came up with a solution and agreed for the mobile phone to be on speaker but kept on the adjacent table so that we are not clearly audible to him. Through the course of the interview, Sneha explained that her boyfriend is indeed demanding, for example, expecting her to drive across the city for his work and to pick up and drop off his family from the airport when they visit. Sneha however, always gives in to his demands because 
she believes that behind his dominant nature is immense love and affection for her. In fact, his acute control over her life is indeed a symbol of their intimate relationship and a testimony to the fact that he considers her family, for such interest and control is only exercised on family members, she explained.

Whilst Sneha's case was one of the extremes, other women also narrated incidents of their boyfriends checking their text messages, emails, and keeping a track of their whereabouts. ${ }^{9}$ It was also not uncommon for women to exercise acute surveillance over their boyfriend as well, by keeping a tab on their phone, email, and social networking profiles. These narrations made it clear that the notion of control is paramount to Indian relationships-even in pre-marital romantic ones. Whilst the burden of accountability usually lies on the family, the young middle class-perhaps in absence of any well-defined template of experiencing these intimacies-reverts to this model of authority and control to define the dynamics of pre-marital encounters. The relationships, therefore, are modeled on familial dynamics with the change that the burden of accountability is shifted from the family to the boyfriend or girlfriend. Moreover, often this is viewed not as a constraining aspect of the relationship but a sign of deep intimacy. In fact, agreeing to be subjected to such surveillance serves as a reasonably important test to qualify for marriage, as it indicates the desire to be a part of a new family.

\section{Resistances and Negotiations}

These acts of disciplining are not always left unquestioned or are not critiqued, and women have various responses to them. It is important here to understand that resistances do not simply warrant an overthrow of structure, though at times that too happens when the woman breaks up the relationship, but also exist in small pockets (Scott 1985, 1990), as women adopt strategies, pick fields of battle, and negotiate within the power structure of their household (Gold and Raheja 1994; Jassal 2012; Jeffery and Jeffery 1996)..$^{10}$ Some women explained to me that they agree to follow the rules and norms regarding dress codes and food at the beginning of the marriage, only to overturn them once they have established themselves in the new household. Some others explained that while they agree to the demands of their boyfriend with regard to his family, they too make demands on his behavior regarding his interaction with their family. Whilst there are also those who claim to conscientiously follow the model of the dutiful wife and daughter-in-law, insofar as their aspiration and desire to be in paid employment is not thwarted.

However, some women did undertake the difficult step of breaking up the relationship, especially when they had reached marriageable age, and were risking their reputation, and agreed to venture on the perhaps long and arduous path of finding a suitable spouse. Rekha, aged 31, narrated that she was in love with Ramesh, who belonged to a different regional and linguistic community and they wanted to marry each other. He arranged to introduce her to his parents, who were not disrespectful towards her, but soon she noticed some changes in her boyfriend's behavior. She said,

Once the marriage was on the cards, I saw him becoming more possessive and he would keep track of every movement. If I was in a bad mood and snap at him he would answer back and say he does not want to be with someone who is so sharptongued. I mean suddenly things began to change. He was close to his mother, so maybe he used to discuss things about me to her. And maybe she didn't think of me to be that suitable or encouraged him to control me? ... Also, earlier he wouldn't ask 
his parents' permission to go out of town with me for a short holiday, but later they were always involved in all our activities. After many months of this constant interference and emotional trauma I decided to call the relationship quits.

Rekha explained that every time she brought up Ramesh's mother's interference in their lives and her apprehensions regarding her mother-in-law's control over their potential marriage, Ramesh would not engage her worries and simply asked her to stop "overthinking" or "overreacting." Rekha claimed that she tried to have a discussion with Ramesh for several months but her pleas always fell on deaf ears, and so she decided to end the relationship. She added that Ramesh accepted her decision because they had been fighting a lot and he too thought that they were rather incompatible. He said that he did indeed love her but he could not see how they would make it work in the future. Rekha strongly suspected that his mother perhaps rationalized this decision for him, and it was her thoughts speaking rather than Ramesh's own, as he indeed agreed to breaking up with little resistance. ${ }^{11}$

\section{The Involvement of Parents}

In an essay entitled "The Family and the Reproduction of Inequality" (1993), Béteille, argues that especially amongst the "service" class (referring to professionals, civil servants, managers and others), certain fundamental changes are occurring in the reproduction of inequality where the family (more than caste) plays an important role. It is therefore important to understand the specific relations of the family, particularly to aspects of modernity that aid in curating experiences of intimacies and processes of spouse-selection. One such dimension of modernity is the use of technology in everyday lives, and particularly the use of the internet for matchmaking. Recent works, such as Titzmann (2013) argue that matrimonial websites propagate a "family-oriented individualism" and Agarwal (2015) explains that these websites in fact enable a new form of "doing kin work." The family, therefore, has not been displaced by modern lifestyles but has been crucially reconfigured in everyday realities (Bhandari 2018). The family, as I argue, also engages in the space of pre-marital relationships in ways that allow it to position itself as being "modern" by not actively deciding the fate of the pre-marital relationship but subtly achieving a desired outcome. It is to be flagged here that this is not the case for all pre-marital relationships, as there are in fact couples that insist on marrying their chosen mate even against the wishes of the parents. However, it is equally important to recognize that the family does influence even pre-marital choices. This is most evident in the fact that during my fieldwork I rarely came across inter-religious premarital relationships. The few that I was made aware of were usually broken off, precisely for the reason that the parents would not have accepted an inter-religious union, even if the chosen partner was well-educated and financially stable. There was more flexibility with regard to inter-caste relations. However, broadly speaking these relationships were between the upper castes, and I did not encounter a single "serious" relationship between a member of an upper caste and one of a so-called lower caste. This resonates with Béteille's argument that the family is indeed an important site of reproduction of inequality, for it ensures that the chosen spouse is also from a similar class and social position. Furthermore, the principle of hypergamy largely governed the "serious" premarital relationships, as the man's family was resistant to his marrying a woman from a higher caste and certainly opposed any plans to marry a woman who was more educated or professionally successful than their son. 
is section, I bring attention to the strategies of self-presentation as modern used by the family as it claims to have a "hands-off" approach in the romantic encounters of its children. Nonetheless, as we see, the family ultimately does ensure that its choice and criteria regarding a suitable spouse are adhered to. A key method by which the family does this is to not explicitly express its disapproval in the language of morality, caste, or community but uses the jargon of rationality, pointing to the logistics or impracticalities of the union.

Mrs. Shete, a highly successful medical doctor, claimed to have always supported her son's choices in relationships. She was in fact fond of his last girlfriend, she exclaimed, who did not belong to the same community as them: she was Bengali, whilst they are Maharastrians. Her son and his girlfriend were negotiating the possibility of a future together, which called for his moving to another city. Mrs. Shete never openly said anything against this to her son. However, she secretly hoped that he would decide not to move away. She said,

I am not the kind of mother who wants to restrict her son, or interfere in his life decisions ... but I wouldn't really want him to move away from me, from this city, forever. I was slightly anxious about this but never said anything to him [her son]... In the end, they couldn't make the relationship work. I was sorry for my son but also relieved that now he would not leave me.

Mrs. Shete never said anything against the girlfriend but she had another strategy in store. She had given them a "deadline to make a decision, and all the while suggested to her son that he join a matrimonial website catering to their community to look for another suitable girl, either from their city or who could move to their city. One of the reasons for this was that she was concerned that her son, aged 30, would be "too old" if they delayed the search process, limiting the opportunity for "good" proposals. Mrs. Shete always spoke highly of her son's girlfriend but also kept bringing his attention to the practical difficulties of this match and the urgency to decide soon lest they both become too old to find suitable spouses if their relationship did not work out. Ultimately, their relationship broke up. It was interesting to note that the son put the entire burden of the collapse of the relationship on himself and his girlfriend, without ever recognizing the role that his mother might have played.

In another similar narrative, I met Abhinav, a consultant at a multinational company, who ended his seven-year relationship. Abhinav belongs to an upper middle-class family in Delhi and his ex-girlfriend Latika is from a well-to-do family in Jaipur. Abhinav explained that over the course of dating, they also had a long-distance relationship and differences began creeping up with regard to personality and likes and dislikes, and so he decided it was time to call it off. At the end of the interview, however, he added in a nonchalant way, "Also, my mother never liked her. She always knew it wouldn't work out." I enquired why his mother did not approve of the relationship, and he said,

She never said anything against her. She didn't think that Latika was a bad girl or anything, but she knew there was a class difference, a difference in background especially socially, and that we would face problems in the future. She of course said to me that the decision is entirely mine, and in fact, she doesn't want any arranged marriage for me. She encourages me to find someone suitable from amongst my friends.

Abhinav is now dating an upper middle class girl from Delhi, whom he met at work. Like Abhinav's family, she too resides in a posh South Delhi bungalow. Abhinav's mother, as he explained, is rather excited about this match, already preparing for the wedding.

South Asia Multidisciplinary Academic Journal, 16 | 2017 
family is acutely aware of the phase of romantic experimentation that young people are engaging in, and their primary concern is to ensure that this space is supervised so that a "self chosen" spouse can also affirm and possibly increase their family status. Whilst they can be active in a space that warrants explicit spouse-selection conversations (such as with matrimonial agents or on websites), they take a more careful approach in pre-marital relationships in order not to antagonize their children by questioning their choice, whilst also ensuring that a suitable spouse, adhering to their standards and criteria, is selected. Herein, lies the modernity of the families.

\section{Conclusion}

Pre-marital relationships are often viewed as spaces of acute individualism or as a social phenomenon that can be a threat to the values and norms of the family. However, through this paper, I have argued that pre-marital experiences in fact mirror marital expectations, duties, and templates as the family comes to scrutinize and shape these relationships. Furthermore, this paper also highlights that the intimacies of the middle class youth and their ideals of marriage are evolving in contexts that are gendered and also influenced by processes of modernization such as the use of technology, global styles of life.

These processes and influences might seem to be pulling in different directions as the individualistic experiences co-exist with familial control, and as the local hierarchies of caste and community coincide with the globalizing contexts of middle class status. However, I argue that this seeming contradiction is in fact constitutive of the modern' and not opposed to it (Dube 2012, 2009). This is because the "modern" does not exist as a sharp disjuncture of time and space, but in fact is composed of oppositions, and begets contestations. This understanding of the modern also defies a unilinear model of progress, for example, one where "love" would champion the sentiments of "arrangement" (Bhandari 2018). It is in this analytical framework of the modern that I situate the current paper, and am motivated to analyze the elongated phase of singlehood that the young adults in India are witnessing, much like other South East Asian societies. ${ }^{12}$ Following from these ethnographic analyses and theoretical underpinnings of the "modern," I offer four broad perspectives through which to understand pre-marital relationships in contemporary India. Firstly, like the work of de Neve (2016), my research is also an ideological rejection of the "individualism" that might be seen to define premarital relationships. I certainly make the argument that the post-liberalization era in India has enabled many opportunities, making use of which, the individuals also experiment with romances and intimacies. Premarital relationships are publicly embraced and dating is indeed widespread. ${ }^{13}$ More importantly, these experiences are viewed as highly individualistic, for they are based on an interpersonal bond between the two individuals, away from the surveillance of the family. However, as I unravel the dynamics of the premarital romances, I highlight that these relationships too are gauged and assessed with regard to their acceptability by the family. Whilst the family might be conspicuously absent from this space, it does influence the dynamics of the relationship.

This brings me to my second point that the moral and operating framework of these relationships is provided by the family. The couple attempts to discipline each other so that the family accepts the partner of choice. In particular, the men groom their 
girlfriends to dress and behave in a manner that is conducive to their family's values and lifestyles. Furthermore, these relationships also follow the rules of authority and control as exercised in the family. The men, for example, maintain strict surveillance on the whereabouts of their girlfriend, at times also directly intervening in their social engagements and expecting them to report back. We thus see that the dynamics of authority and control generally espoused and exercised by the parents over their children are now emulated by the romantic couple.

Thirdly, the family also appropriates these romantic encounters to self-fashion itself as being modern. It presents itself as non-confrontational and non-authoritarian and instead of rejecting a union of choice, it implements strategies to make their opinion count, and in due process decide the future of the pre-marital relationship.

41 Finally, it is also amply clear that marriage remains central to the selfhood of young individuals. The young middle class certainly explore and experience various forms of romantic relationship, yet they continue to construct and present their selves along the norms and rules of marriageability, reiterating the importance of marriage in their social and cultural worlds.

The pre-marital phase of romance is surely outside the direct purview of the family and resonates with an affective desire for individualism. However, as Donner and Santos point out, "the language of romantic love and 'affective individualism,' draws on a conceptual framework that does not separate individuals from collectives or affect from material and self-interest" (2016:1130). My research, as presented in this article, also reveals that the notion of family is central to the construction of marriageability of the upwardly mobile middle-class youth. Whilst the individuals might experience pre-marital relationships as borne out of a "new" era of opportunities, the stability and framework upon which these relationships are actualized continue to be provided by the family.

\section{BIBLIOGRAPHY}

Agrawal, Anuja. 2015. “Cyber-Matchmaking Among Indians: Re-Arranging Marriage and Doing

'Kin-Work."' South Asian Popular Culture 13(1):15-31.

Baviskar, Amita and Raka Ray. 2011. Elite and Everyman: The Cultural Politics of the Indian Middle Classes. New York and Delhi: Routledge.

Beck, Ulrich. 1992. Risk Society: Towards a New Modernity, edited by M. Ritter. London: Sage.

Beck, Ulrich. 1994. Reflxive Modernization: Politics, Tradition and Aesthetics in the Modern Social Order. Cambridge: Polity Press.

Beck, Ulrich. 2000. "The Cosmopolitan Perspective: Sociology of the Second Age of Modernity." The British Journal of Sociology 51(1):79-105.

Béteille, André. 1993. “The Family and the Reproduction of Inequality.” Pp. 435-51 in Family, Kinship and Marriage in India, edited by P. Uberoi. New Delhi: Oxford University Press. 
Bhandari, Parul. 2014. "Spouse-Selection in New Delhi: A Study of Upper Middle Class Marriages." PhD dissertation, University of Cambridge.

Bhandari, Parul. 2017. “Towards a Sociology of Indian Elites: Marriage Alliances, Vulnerabilities, and Resistance in Bollywood." Society and Culture in South Asia 3(1).

Bhandari, Parul. Forthcoming. "Makings of Modern Marriage: Choice, Family and the Matchmakers." In Exploring Indian Modernities: Ideas and Practices, edited by P. Bhandari and L. Choukroune. New Delhi: Springer.

Brosius, Christiane. 2010. India's Middle Class: New Forms of Urban Leisure, Consumption and Prosperity . London and New York: Routledge Kegan and Paul.

Brosius, Christiane. 2013. "Love Attacks: Romance and Media Voyeurism in Public Domain." Pp. 255-86 in Sexuality Studies: Oxford India Studies in Contemporary Society, edited by S. Srivastava. New Delhi: Oxford University Press.

Deshpande, Satish. 2003. Contemporary India: A Sociological View. New Delhi: Viking.

Dickey, Sara. 2011. "The Pleasures and Anxities of Being in the Middle: Emerging Middle-Class Identites in Urban South India.” Modern Asian Studies 3(August 2011):559-99.

Donner, Henrike. 2011. Being Middle-Class in India: A Way of Life. London and New York: Routledge. Donner, Henrike. 2016. "Doing It Our Way: Love and Marriage in Kolkata Middle-Class Families." Modern Asian Studies 50(4):1147-89.

Donner, Henrike and Goncalo Santos. 2016. "Love, Marriage, and the Intimate Citizenship in Contemporary China and India: An Introduction.” Modern Asian Studies 50(4):1123-46.

Dube, Leela. 1988. "On the Construction of Gender: Hindu Girls in Patrilineal India." Pp. 166-92 in Socialisation, Education and Women, edited by K. Chanana. Hyderabad: Orient Longman.

Dube, Saurabh. 2009. Enchantments of Modernity: Empire, Nation, Globalization. New Delhi: Routledge. Dube, Saurabh. 2012. "Modern Makeovers: An Introduction." Pp. 1-25 in Handbook of Modernity in South Asia, edited by S. Dube. New Delhi: Sage.

Dwyer, Rachel. 2000. All You Need Is Money, All You Want Is Love: Sex and Romance in Modern India. London: Cassell.

Fernandes, Leela. 2006. India's New Middle Class: Democratic Politics in an Era of Political Reform. Minneapolis: University of Minnesota Press.

Fernandes, Leela. 2011. "Hegemony and Inequality: Theoretical Reflections on India's 'New' Middle Class." Pp. 58-82 in Elite and Everyman: The Cultural Politics of the Indian Middle Classes, edited by A. Baviskar and R. Ray. New Delhi: Routledge.

Fruzetti, Linda. 1982. The Gift of a Virgin: Women, Marriage and Ritual in a Bengali Society. New Delhi: Oxford University Press.

Fuller, Chris. J. and Haripriya Narasimhan. 2008. "Companionate Marriage in India: The Changing Marriage System in Middle-Class Brahman Subcaste." Journal of the Royal Anthropological Institute 14:736-54.

Fuller, Chris. J. and Haripriya Narasimhan. 2014. Tamil Brahmins: Making of a Middle-Class Caste. Chicago: University of Chicago Press.

Gershon, Ilana. 2011. "Un-Friend My Heart: Facebook, Promiscuity, and Heartbreak in a Neoliberal Age.” Anthropological Quarterly 84(4):865-94. 
Giddens, Anthony. 1991. Modernity and Self Identity: Self and Society in Late Modern Age. London: Polity Press.

Gold, Ann Grodzins and Gloria Goodwin Raheja. 1994. Listen to the Heron's Words. Berkeley: University of California Press.

Gooptu, Nandini. 2013. Enterprise Culture in Neoliberal India: Studies in Youth, Class, Work and Media. Oxford: Routledge.

Grover, Shalini. 2011. Marriage, Love, Caste and Kinship Support. Delhi: Oriental Blackwell.

Hirsch, Jennifer and Holly Wardlaw. 2006. Modern Loves: The Anthropology of Romantic Courtship and Companionate Marriages. Michigan: University of Michigan Press.

Jaffrelot, Christophe and Peter Van der Veer. 2008. "Introduction." Pp. 11-34 in Patterns of Middle Class Consumptions in India and China, edited by C. Jaffrelot and P. van der Veer. New Delhi: Sage.

Jassal, Smita Tewari. 2012. Unearthing Gender: Folksongs of North India. Durham and London: Duke University Press.

Jeffery, Patricia and Roger Jeffery. 1994. “Killing My Heart's Desire: Education and Female Autonomy in Rural North India." Pp. 125-71 in Women as Subjects: South Asian Histories, edited by N. Kumar. Charlottesville: University Press of Virginia.

Jeffery, Patricia and Roger Jeffery. 1996. Don't Marry Me to a Plowman: Women's Everyday Lives in Rural North India. Oxford: Westview Press.

Jodhka, Surinder. 2013. Interrogating India's Modernity: Democracy, Identity, and Citizenship. New Delhi: Oxford University Press.

Jodhka, Surinder and Aseem Prakash. 2016. The Indian Middle Class. New Delhi: Oxford University Press.

Jones, Gavin. 2007. "Delayed Marriage and Very Low Fertility in Pacific Asia." Population and Development Review 33(3):453-78.

Jones, Gavin, Terrence Hull, and Maznah Mohamad. 2011. Changing Marriage Patterns in Southeast Asia: Economic and Socio-Cultural Dimensions. London: Routledge.

Kabamalan, Maria Midea M. 2011. “Cohabitation and Poverty in Phillipines." Pp. 205-17 in Changing Marriage Patterns in Southeast Asia: Economic and Socio-cultural Dimensions, edited by G. W. Jones, T. Hull, and M. Mohamad. London: Routledge.

Kapur, Devesh and Milan Vaishnav. 2014. "Being Middle Class in India.” The Hindu, December 9.

Koh, Eng Chuan. 2011. "The State of Marriage in Singapore.” Pp. 218-33 in Changing Marriage Patterns in Southeast Asia: Economic and Socio-cultural Dimensions, edited by G. W. Jones, T. Hull, and M. Mohamad. London: Routledge.

Lietchy, Mark. 2003. Suitably Modern: Making New Middle Class Culture in a New Consumer Society. Princeton, NJ: Princeton University Press.

Mazzarella, William. 2002. "Cindy at Taj: Cultural Enclosure and Corporate Potentateship in an Era of Globalization.” Pp. 387-99 in Everyday Life in South Asia, edited by M. Diane and S. Lamb. Bloomington: Indiana University Press.

Mazzarella, William. 2003. Shoveling Smoke: Advertising and Globalisation in Contemporary India. New Delhi: Oxford University Press.

Miller, Daniel. 2011. Tales from Facebook. Cambridge: Polity Press. 
de Neve, Geert. 2016. "The Economies of Love: Love Marriage, Kin Support, and Aspiration in a South Indian Garment City.” Modern Asian Studies 50(4):1220-49.

Rangaswamy, Nimmi and Edward Curtell. 2012. "Anthropology, Development, and ICTs: Slums, Youth, and the Mobile Internet in Urban India." Information Techonologies and International Development 9(2):51-63.

Saavla, Minna. 2012. Middle-Class Moralities: Everyday Struggle over Belonging and Prestige in India. New Delhi: Orient BlackSwan.

Scott, James C. 1985. Weapons of the Weak: Everyday Forms of Peasant Resistance. New Haven and London: Yale University Press.

Scott, James C. 1990. Domination and the Arts of Resistance. New Haven and London: Yale University Press.

Sharangpani, Mukta. 2010. "Browsing for Bridegrooms: Matchmaking and Modernity in Mumbai." Indian Journal of Gender Studies 17(2):249-76.

Situmorang, Augustina. 2011. "Delayed Marriage among Lower Socio-Economic Groups in an Indonesian Industrial City." Pp 83-98 in Changing Marriage Patterns in Southeast Asia: Economic and Socio-cultural Dimensions, edited by G. Jones, T. Hull, and M. Mohamad. London: Routledge.

Srivastava, Sanjay. 2014. Entangled Urbanism: Slum, Gated Community and Shopping Mall in Delhi and Gurgaon. New Delhi: Oxford University Press.

Therborn, Göran. 2013. "Family Systems of the World: Are They Converging?" Pp. 3-19 in The Blackwell Companion to the Sociology of Families, edited by J. Treas, J. Scott, and M. Richards. Oxford: Blackwell Publishers.

Titzmann, Fritzi-Marie. 2011. "Matchmaking 2.0: The Representation of Women and Female Agency in the Indian Online Matrimonial Market." Internationales Asienforum: International Quarterly for Asian Studies 42(3-4):239-56.

Titzmann, Fritzi-Marie. 2013. “Changing Patterns of Matchmaking: The Indian Online Matrimonial Market.” Asian Journal of Women's Studies 19(4):64-94.

To, Sandy. 2013. “Understanding Sheng Nu ('Leftover Women'): The Phenomenon of Late Marriage Among Chinese Professional Women.” PhD dissertation, University of Cambridge.

Twamley, Katherine. 2014. Love, Marriage, Intimacy among Gujarati Indians: A Suitable Match. Basingstoke: Palgrave.

Uberoi, Patricia. 2009. Freedom and Destiny: Gender, Family and Popular Culture in India. New Delhi: Oxford University Press.

Uberoi, Patricia and Amita Tyagi Singh. 2006. "Learning to 'Adjust': The Dynamics of Post-Marital Romance." Pp. 217-47 in Freedom and Destiny: Gender, Family and Popular Culture in India, edited by P. Uberoi. New Delhi: Oxford University Press.

Varma, Pavan. 2007. The Great Indian Middle Class. New Delhi: Penguin.

van Wessel, Margit. 2004. "Talking About Consumption: How an Indian Middle Class Dissociates from Middle Class Life." Cultural Dynamics 16(93-116). 


\section{NOTES}

1. Recent works (Jones 2007; Jones, Hull, and Mohamad 2011; Koh 2011) have brought attention to this phase that has been termed "elongated singlehood" as it has come to be a new and widespread phenomenon, especially in southeast Asian societies. These studies explain the impact of this phase on the state of marriage.

2. For further discussion on the conception of the modern as seen inherently based on contradictions and contestations, which this article follows, refer to the works of Dube (Dube $2009,2012)$. Dube argues that it is important to view the modern not simply as a disjuncture in time and space, which is not to say that the opposition between "modern" and "traditional" is to be rejected as analytically flawed. Instead, he explains that modernity is a process of the past and present, and a checkered narrative that is constitutive of contestations and contradictions (2012:5, 6).

3. Recent scholarship has queried the significance of the term "middle," for it has been established that the middle class in fact constitutes a small segment of the Indian population (Deshpande 2003) and, in fact, is far from a homogeneous category, as the income levels, for one, are rather varied (Jodhka 2013; Kapur and Vaishnav 2014). Owing to this, some scholars prefer to use the term "middle-classes" to denote the heterogeneous composition of this class. Scholarship also questions the economic basis of defining the middle class, arguing that it is more a social and historical category than an economic one (Baviskar and Ray 2011; Dickey 2011; Jodhka 2013).

4. Whilst the problem of trust and access to male informants by a female researcher exists, there are other ways to ensure that the male voice can be adequately represented, as through analysis of the virtual media. For the latest discussion on this see Rangaswamy and Curtell (2012).

5. These leisure cultures and "away from home" spaces in some ways become markers of a neoliberal identity since, for the middle class youth, "transformation from planned economy to open market was also a shift from the imperative of serving the nation, to pleasure and consumption, as progress" (Brosius 2013, 266-67). For further discussion on understanding the "new" middle class and its penchant for consumption see Brosius (2010); Fernandes (2006); Jaffrelot and Van der Veer (2008); Mazzarella (2003); van Wessel (2004).

6. For further information on the intricate relationship between popular culture on the one hand and marriage and family norms on the other, see Uberoi (2009) and Dwyer (2000).

7. This article has used pseudonyms for all interviewees.

8. The Chartered Accountancy Examination in India is considered one of the toughest of CA exams. It is a three level examination, with each level consisting of six to seven subjects that are often divided into two groups. It takes anywhere between four to eight years for students to pass all sets of examinations.

9. For further discussion on these aspects of control and surveillance facilitated by social media, see Gershon (2012).

10. Jeffery and Jeffery point out that whilst women remained silent on matters of household economics, they may have "turned to spitfires when speaking of their husbands' moral transgressions" (1994:19). Gold and Raheja (1994) and Jassal (2012) find women's resistance in proverbs and songs.

11. To decide to leave a relationship at the age of 30 was certainly not easy for Rekha. However, she explained that her family is supportive and insist that she finds a suitable match, rather than marry due to pressure of age and then decide to divorce. Rekha did enter the formal space of spouse-selection as she was registered on a matrimonial website, though her parents also encouraged her to look for someone on her own. Whilst women's parents are accepting a later age at marriage, the man's parents continue to have a preference for finding a bride that is 
younger than the man. The general view remains that an older unmarried woman is stubborn and will not easily adjust to a new family situation. In some ways, this resembles the phenomenon of "left-over" women in China, that is, the highly educated women who are less desirable for marriage (To 2013).

12. The aim of this paper is not to position the pre-marital relationships of young Indians vis-àvis the romantic intimacies of other societies, to tease out the similarities or differences. Nor does this paper follow the binary conceptualization that explains romantic intimacies as definite indicators of a progress from "traditional societies" to "modern societies." Nonetheless, there seem to be certain similarities, especially with other South East Asian societies (G. Jones 2007; G. Jones, Hull, and Mohamad 2011; Kabamalan 2011; Situmorang 2011). For further debate on convergence of family types, see Therborn (2013).

13. It is important to note here that I am not making the case that premarital relationships have increased in contemporary India. Instead, the change is in the public acceptance and visibility of these relationships, as couples openly display their affection in public and the parental generation too is aware of these encounters, though they might or might not approve of them.

\section{ABSTRACTS}

This paper is an inquiry into a form of intimate relationship that is garnering much public attention in contemporary India, namely, the pre-marital relationship. In order to query the rhetoric of individual agency and "freedom" that often gets associated with pre-marital relationships, this paper explores the family's involvement in pre-marital relationships of young adults aged 24-31. The paper argues that though pre-marital relationships often fashion themselves as a disjuncture from the narrative of marriage, in reality, they model themselves on structures and expectations of a marital union. This paper also pays attention to the ways in which families position themselves vis-à-vis pre-marital relationships. Specifically, it discusses the strategies by which the family can obstruct or encourage certain pre-marital relationships over others, thereby highlighting the bearing of the family's involvement in changing the course of a relationship: either from a non-serious form of relationship to a committed one, or leading to the breaking up of the relationship.

\section{INDEX}

Keywords: pre-marital relationships, family, marriage, modern, middle class

\section{AUTHOR}

\section{PARUL BHANDARI}

St. Edmund's College and The Center of South Asian Studies (CSAS), University of Cambridge, UK; Center for Social Sciences and Humanities (CSH), New Delhi 